123. Roland Scholl und M. Brenneisen: Ueber einen Begleiter des Brompikrins.

(Eingegangen am 22. März; mitgetheilt in der Sitzung von Hrn. E. Tāuber.)

Wie in der vorhergehenden Abhandlung erwähnt wurde, ist dem durch Destillation von Pikrinsäure mit Bromkalklösung entstehenden Brompikrin ein Körper beigemengt, der wahrscheinlich mit Dibromdinitromethan identisch ist.

Der erste zur Isolirung dieses vermutheten Begleiters angestellte Versuch war die vorsichtige Destillation des rohen Brompikrins unter vermindertem Druck. Dabei ging es unter $10.5 \mathrm{~mm}$ glatt und unzersetzt bei $76^{0}$ über $^{1}$ ). Diese Beobachtung sprach zwar für die Einheitlichkeit der Substanz, sie schien uns aber nicht entscheidend zu sein, da ein beigemengter Körper, wenn er mit den Brompikrindämpfen flüchtig und nur in sehr geringer Menge vorhanden war, den Siedepunkt nicbt wesentlich hätte zu beeinträchtigen brauchen.

Wirklich haben wir auch auf auderem Wege einen solchen Begleiter aufgefunden. Schüttelt man nämlich das rohe Brompikrin mit verdünnter Kalilauge, so nimmt diese die gesuchte Verbindung in Form eines gelben Kaliumsalzes in sich anf, und das Brompikrin kann auf diese Weise durch 10-20-maliges Durchschütteln gereinigt werden, da es von verdünnten wässrigen Alkalien gar nicht, von concentrirten nur sehr langsam angegriffen wird.

Aus den verdünnten alkalischen Laugen liess sich das gelbe $\mathrm{Ka}$ liumsalz nicht gewinnen, bei Auwendung einer concentrirten Lauge dagegen leicht auf folgende Weise. $10 \mathrm{~g}$ rohes Brompikrin wurden unter Eiskühlung in Verlaufe ron etwa 20 Minuten in $50 \mathrm{~g}$ fünfzigprocentige Kalilauge eingetropft, die zur feinen Vertheilung des Oeles fortwährend kräftig geschüttelt wurde. Nach 1/4-stüudigem Stehen des eine Emulsion bildenden Reactionsgemisches in Eiswarser wurde unter fortgesetzter Kühlung Kohlensäure bis zur Sättigung eingeleitet, weil sich das Product sonst, wie die Erfahrung lehrte, beim Absaugen in der starken Lauge vollständig zersetzte. Es hatte sich ein gelbes Salz abgeschieden, das nun auf dem Filter gesammelt und so lange mit Methylalkohol gewaschen wurde, bis der Geruch nach Brounpikrin verschwunden war. In dem Filtrate befand sich ein Oel, welches unter $17 \mathrm{~mm}$ Druck bei $81-82^{\circ}$ destillirte, also unverändertes Brompikrin war.

Das ausgeschiedene Salz stellte nach zweimaligem rorsichtigem Umkrystallisiren aus heissem Wasser gelbe glänzeude Krystalle dar, die bei $155^{\circ}$ explodirten.

$\mathrm{CN}_{2} \mathrm{O}_{4} \mathrm{BrK}$. Ber. K 17.4. Gef. K I6.9.

t) Unter gewöhnlichem Drucke siedet es nicht unzersetzt, unter $118 \mathrm{~mm}$ nach Levy und Jedlicka (Ann. der Chem. 249, 8j) bei 127. 
Die Analyse sowie die von uns durchgefübrte Umwandlung des Salzes in Dinitromethankalium vermittelst einer alkalischen Lösung von arseniger Säure bewiesen, dass das Salz ans Bromdinitromethankalium bestand.

Unter der Voraussetzung, dass diese Bildung des Kaliummonobromdinitromethans auf keinem verwickelten Vorgange beruht, kann der Begleiter des Brompikrins nur Monobrom- oder Dibrom-Dinitromethan sein. Beide Körper geben bekanntlich mit Kalilange Monobromdinitromethankalium. Da aber Monobromdinitromethan, wenn es bei der Einwirkung von Bromkalklösung auf Pikrinsäure entstände, wohl nicht unverändert bleiben, sondern weiter in Dibromdinitromethan übergehen würde, da es sich ferner aus einer alkalischen Flüssigkeit durch Wasserdampf gar nicht übertreiben lassen würde, so muss man wohl annehmen, dass der Begleiter des Brompikrins Dibromdinitromethan sei.

Seine Bildung kann man sich durch die Annahme erklären, es entstehe durch Einwirkung des im Ueberschusse vorhandenen Kalkes auf Pikrinsäure oder auf das gebildete Brompikrin eine kleine Menge Calciumnitrit, das dann mit dem Brompikrin entsprechend der Gleichung:

$$
2 \mathrm{C}\left(\mathrm{NO}_{2}\right) \mathrm{Br}_{3}+\mathrm{Ca}\left(\mathrm{NO}_{2}\right)_{2}=\mathrm{CaBr}+2 \mathrm{C}\left(\mathrm{NO}_{2}\right)_{3} \mathrm{Br}_{2} \text {, }
$$

unter Bildung von Dibromdinitromethan reagire. Es wäre derselbe Vorgang, wie er sich bei der Pildung des Dinitroäthankaliums aus Bromnitro- oder Dibromnitro-Aethan und Kaliumnitrit bei Gegenwart von alkoholischem Kali vollzieht ${ }^{1}$ ).

Karlsrube, Chemisches Laboratorium der techn. Hochschule.

\section{O. Loew: Berichtigung.}

(Eingegangen am 14. Mărz.)

Bezüglich der in diesen Berichten Bd. 30, S. 3208, sich findeuden Bemerkung Kossel's, dass Ba umann die Ansichten von Loew nnd Bokorny widerlegt habe, erlaube jch mir auf die Notiz hinzuweisen, welche ich in der Chemikerzeitung 1897, No. 58, veröffentlichte, nachdem Kossel diese Meinung bereits an einem anderen Orte ausgesprochen batte.

Eine ausfübrliche Darlegung des gegenwärtigen Standes von der Frage nach der Labilität von Proteïnstoffen in Pflanzenzellen findet sich in meiner Schrift: sThe Energy of Living Protoplasm, London, 1896 *

1) Ter Meer, Ann. d. Chem. 181, 1. 